\title{
latrogenic hypoglycemia in a patient with type 2 diabetes and Münchhausen syndrome
}

\section{ABSTRACT}

The coexistence of insulinoma and type 2 diabetes is rare, however it is reported in the literature. Episodes of hypoglycemia in patients with type 2 diabetes are, to some extent, part of the disease due to the therapy and the use of all hypoglycemic drugs including diet intervention. However, persistent episodes require diagnosis even after discontinuation of diabetes therapy. We present a patient with iatrogenic hypoglycemia and type 2 diabetes in Münchhausen syndrome. The coexistence of type 2 diabetes and insulinoma was suspected in that patient but the clinical picture suggested exogenous administration of hypoglycemic drugs, which was finally confirmed. Factitious hypoglycemia was a symptom of mental disorders such as a Münchhausen syndrome. (Clin Diabetol 2018; 7, 6: 279-281)

Key words: hypoglycemia, insulinoma, Münchhausen syndrome

\section{Introduction}

Hypoglycemia is a serious diagnostic and clinical problem, especially if it is recurrent and severe. In diabetic patients, the main predisposing factor for hypoglycemia is the disease treatment mode (inadequate doses of hypoglycemic agents or insulin).

\footnotetext{
Address for correspondence:

Edyta Cichocka PhD

Samodzielny Publiczny Szpital Kliniczny nr 1

Oddział Chorób Wewnętrznych, Diabetologii I Nefrologii

ul. 3 Maja 13/15, 41-800 Zabrze

Mobile: +48530032 206

e-mail: ecichocka@sum.edu.pl

Clinical Diabetology 2018, 7, 6, 279-281

DOI: 10.5603/DK.2018.0030
}

Received: 02.12.2018

Accepted: 12.12 .2018
Hypoglycemia is not always an adverse effect of the treatment of diabetes. It can also occur in healthy individuals during long-term starvation, strenuous physical activity or pregnancy. It may also be associated with diseases other than diabetes or may be a side effect of treatment (other than antihyperglycemic) and may require investigation for diabetes. Differential diagnosis should also include insulinoma, which is a relatively rare neuroendocrine tumor. Hypoglycemia is the primary symptom of this tumor that is mostly benign (90\%). Typically, insulinoma is characterized by the Whipple triad, including increased insulin levels with associated hypoglycemia $<50 \mathrm{mg} / \mathrm{dl}$ and normalization of glycemia after oral glucose administration [1].

The coexistence of insulinoma and type 2 diabetes is rare, however it is reported in the literature [2-4]. Episodes of hypoglycemia in patients with type 2 diabetes are, to some extent, part of the disease due to the therapy and the use of of all hypoglycemic drugs including diet intervention. However, persistent episodes require diagnosis even after discontinuation of diabetes therapy.

\section{Case report}

A 40-year-old obese patient with recurrent hypoglycemia, frequently hospitalized in the departments of internal medicine was transferred to the department of diabetology for further diagnosis. The patient was a childless single woman who lived with her mother and was a teacher by profession.

The medical history revealed type 2 diabetes diagnosed the previous year that was initially treated with a sulfonylurea (glimepiride) which was discontinued 3 months prior to hospitalization due to the occurrence of hypoglycemic episodes. In the interim, the patient was also administered with insulin (two injections of a biphasic suspension of the insulin analog in the 
ratio 30/70). This treatment was also discontinued as reported by the patient. The subject did not tolerate metformin.

Additionally, the medical history revealed hypertension, bronchial asthma, hormonally inactive left adrenal adenoma, autoimmune thyroiditis and hypothyroidism during substitution treatment with L-thyroxine.

On admission to the department of diabetology, the patient was in good condition. Physical examination did not reveal any abnormality except obesity (BMI 38 $\mathrm{kg} / \mathrm{m}^{2}$ ). Laboratory tests showed decreases in glycemia to $15 \mathrm{mg} / \mathrm{dl}$ with a concomitant increase in insulin concentration to $86.28 \mathrm{iU} / \mathrm{ml}(\mathrm{N}: 2.6-24.9)$ and normal C-peptide level of $2.84 \mathrm{ng} / \mathrm{ml}$ (N: 1.1-4.4). The patient required the insertion of a central venous catheter and continuous glucose infusion. Decrease in glycemic levels occurred independently of meals and was also observed at night. The injection sites were not found despite an extensive search due to the suspicion of exogenous insulin administration. Contrast-enhanced abdominal CT did not reveal areas of abnormal contrast enhancement in the pancreas or other abdominal organs. The CT imaging revealed only segmental thickening of the proximal medial branch of the left adrenal gland (previously described as hormonally inactive adrenal adenoma). Endoscopic ultrasound (EUS) also showed normal pancreas. Due to the decrease in circadian cortisol level $(8.00$ a.m. $-5.73 \mu \mathrm{g} / \mathrm{dl}, 8.00$ p.m. -4.42 $\mu \mathrm{g} / \mathrm{dl})$, the patient was transferred to the Department of Endocrinology in Katowice, Poland for further diagnosis. In the department, recurrent hypoglycemia was also observed, which was associated with the visits of the patient's mother. Insulin and C-peptide levels assessed during hypoglycemia are given in the Table 1 .

Frequent attempts to discuss the problem with self-medication (sulfonylurea and/or insulin) resulted in marked deterioration in mood in the patient who became dysphoric, tearful, and reported suicidal thoughts. Testing for the presence of sulfonylurea and the toxicology testing for hypnotic and sedative drugs confirmed sulfonylurea in the urine. However, benzodiazepines were detected in the serum (259 ng/dl). Serum proinsulin level was $22.4 \mathrm{pmol} / \mathrm{l}$ (N: fasting $<7.31 \mathrm{pmol} / \mathrm{l}$ ). Decrease in cortisol level (circadian rhythm) with a normal synacthen test result was most likely related to the use of psychiatric drugs.

In view of the above circumstances, the patient was referred for psychiatric consultation despite her lack of consent. The consultant psychiatrist diagnosed a depressive episode and addiction to hypnotic and sedative drugs.

The patient's personal belongings were searched, and insulin and glimepiride were found. The patient
Table 1. Insulin and C-peptide levels assessed during hypoglycemia

\begin{tabular}{lccc}
\hline Hour & $\begin{array}{c}\text { Glucose } \\
{[\mathrm{mg} / \mathrm{dl}]}\end{array}$ & $\begin{array}{c}\text { Insulin [uU/ml] } \\
\text { N: 8-25 }\end{array}$ & $\begin{array}{c}\text { C-peptide } \\
{[\mathrm{mg} / \mathrm{dl}]} \\
\text { N: } \mathbf{0 . 7 8 - 5 . 1 9}\end{array}$ \\
\hline 2 p.m. & $38 \mathrm{mg} / \mathrm{dl}$ & 62.00 & 7.56 \\
10 p.m. & $40 \mathrm{mg} / \mathrm{dl}$ & 34.50 & 5.02 \\
5 a.m. & $31 \mathrm{mg} / \mathrm{dl}$ & 27.60 & 2.99 \\
1 p.m. & $39 \mathrm{mg} / \mathrm{dl}$ & 3.38 & 230.10 \\
\hline
\end{tabular}

confirmed the use of these drugs during subsequent hospitalizations and indicated the region of the fingertips as the site of insulin delivery, thus wanting to hide possible traces of the injection.

The subject was transferred to the department of psychiatry for further diagnosis and treatment due to mental disorders in the form of a depressive episode with suicidal thoughts and increased emotional lability and also due to the suspicion of Münchhausen syndrome.

\section{Discussion}

Hypoglycemia, which is related to the therapy with insulin and oral antihyperglycemic drugs, may be a significant clinical problem. In non-diabetic patients, it requires investigation for diabetes. Differential diagnosis should always include insulinoma (insulin-secreting tumor). Currently, a 72-h fasting test is the "gold standard" for the diagnosis of this tumor. In patients with type 2 diabetes with insulinoma, a reduced need for hypoglycemic medication(s) and even normalization of glycemia may be initially observed [3].

The coexistence of type 2 diabetes and insulinoma was suspected in the patient. However, the clinical picture suggested hypoglycemia due to exogenous administration of hypoglycemic drugs, which was finally confirmed. Hypoglycemia with very high insulin level and decreased C-peptide level is pathognomic of exogenous insulin administration.

An overdose of sulfonylureas may, in turn, result in increased insulin and C-peptide levels. Increased levels of proinsulin are found in obese patients and are associated with endogenous hyperinsulinemia, which in our patient may have been the result of the use of sulfonylureas. Based on the clinical picture, type $A$ insulin resistance was also excluded due to the fact that the patient was obese, did not present with menstrual disorder; nor did the patient have skin changes typical of acanthosis nigricans [5].

latrogenic hypoglycemia should be considered in all patients who have access to insulin or sulfonylureas. Factitious hypoglycemia is the most common 
symptom of mental disorders in patients who want to draw attention to themselves and is typical of Münchhausen syndrome [6]. The syndrome, also known as a factitious disorder, is defined as repeated fabrication of physical or self-induced symptoms to receive attention from medical personnel. This deliberate and conscious behavior is based on manipulation and occurs in individuals with a particular personality type (narcissistic features, borderline personality or antisocial personality traits) [6-8]. Our patient had depressive disorders, and finally admitted to excessive use of hypnotic and sedative drugs. During hospital stays, the patient used her mother to obtain more medications. Frequent hospitalizations were most likely due to the fact that the patient wanted to fill the emotional void and tried to draw attention to herself.

\section{Disclosure information for all authors}

I certify that neither I nor my co-authors have a conflict of interest as described above that is relevant to the subject matter or materials included in this Work.

\section{REFERENCES}

1. Câmara-de-Souza AB, Toyoshima MTK, Giannella ML, et al. Insulinoma: A retrospective study analyzing the differences between benign and malignant tumors. Pancreatology. 2018; 18(3): 298-303, doi: 10.1016/j.pan.2018.01.009, indexed in Pubmed: 29452754.

2. Kamocki ZK, Wodyńska NA, Pryczynicz A. Co-existence of insulinoma and diabetes: A case report. Oncol Lett. 2014; 8(4): 1697-1700, doi: 10.3892/ol.2014.2338, indexed in Pubmed: 25202394

3. Ghafoori S, Lankarani M. Insulinoma in a patient with type 2 diabetes mellitus. Acta Med Iran. 2015; 53(5): 317-319, indexed in Pubmed: 26024708.

4. Assyov Y, Gateva A, Zaharieva E, et al. Concomitant insulinoma and type 2 diabetes mellitus diagnoses: a case report. J Diabetes. 2016; 8(5): 740-742, doi: 10.1111/1753-0407.12409, indexed in Pubmed: 27075402.

5. Moller DE, Cohen O, Yamaguchi Y, et al. Prevalence of mutations in the insulin receptor gene in subjects with features of the type A syndrome of insulin resistance. Diabetes. 1994; 43(2): 247-255, indexed in Pubmed: 8288049.

6. Burton MC, Warren MB, Lapid MI, et al. Münchhausen syndrome by adult proxy: a review of the literature. J Hosp Med. 2015; 10(1): 32-35, doi: 10.1002/jhm.2268, indexed in Pubmed: 25274180.

7. Trenque T, Hoizey G, Lamiable D. Serious hypoglycemia: Münchhausen's syndrome? Diabetes Care. 2001; 24(4): 792-793, indexed in Pubmed: 11315856.

8. Ameh V, Speak N. Factitious hypoglycaemia in a nondiabetic patient. Eur J Emerg Med. 2008; 15(1): 59-60, doi: 10.1097/ MEJ.0b013e3282aa3f70, indexed in Pubmed: 18180671. 